\title{
Childhood Scurvy: A Pediatric Rheumatology Perspective
}

DAX G. RUMSEY, MD, Pediatric Resident; ALAN M. ROSENBERG, MD, Professor of Pediatrics, Division of Rheumatology, Department of Pediatrics, University of Saskatchewan, Saskatoon, Saskatchewan, Canada. Address correspondence to Dr. A.M. Rosenberg, Department of Pediatrics, Royal University Hospital, 103 Hospital Drive, Saskatoon, Saskatchewan S7N 0W8, Canada. E-mail: alan.rosenberg@usask.ca. J Rheumatol 2013;40:201-2; doi:10.3899/jrheum.120900

Vitamin C deficiency can result in scurvy, a condition that can mimic a rheumatic disease. In humans the L-gul-ono- $\gamma$-lactone oxidase gene prevents coding for the enzyme required to convert glucose to ascorbic acid (vitamin C) ${ }^{1,2}$. Consequently, humans require exogenous vitamin C. Scurvy can occur in children whose diet is restricted as a consequence of developmental or socioeconomic circumstances ${ }^{3,4}$. Musculoskeletal and vascular manifestations associated with scurvy can prompt referrals to pediatric rheumatology clinics.

At age 8 years an autistic boy presented with a 3-month history of progressively worsening ankle pain, tenderness, swelling, and warmth and increasingly inflamed and bleeding gingiva. The child's diet was restricted to a small number of foods and excluded fruits and vegetables.

Examination revealed swollen and friable gingiva (Figure 1) and periarticular soft-tissue swelling involving knees and ankles with associated joint warmth, tenderness, and intraarticular effusions. Blood ascorbic acid level was low (22 $\mu \mathrm{mol}$; normal $23-114 \mu \mathrm{mol})$. Knee radiographs
(Figure 2) showed dense calcification of the provisional zones of ossification (line of Frankel).

The constellation of features indicated the diagnosis of scurvy. With oral vitamin C supplementation, gingival and musculoskeletal symptoms and signs resolved.

Scurvy, which is promptly curable with supplemental vitamin $\mathrm{C}$, should be considered in the differential diagnosis of an at-risk child presenting with debilitating musculoskeletal features, particularly when associated with gingival and cutaneous bleeding.

\section{REFERENCES}

1. Levine M. New concepts in the biology and biochemistry of ascorbic acid. N Engl J Med 1986;314:892-902.

2. Drouin G, Godin JR, Page B. The genetics of vitamin C loss in vertebrates. Current Genomics 2011;12:371-8.

3. Weinstein M, Babyn P, Zlotkin S. An orange a day keeps the doctor away: Scurvy in the year 2000. Pediatrics 2001;108:E55.

4. Heymann WR. Scurvy in children. J Am Acad Dermatol 2007;57:358-9.

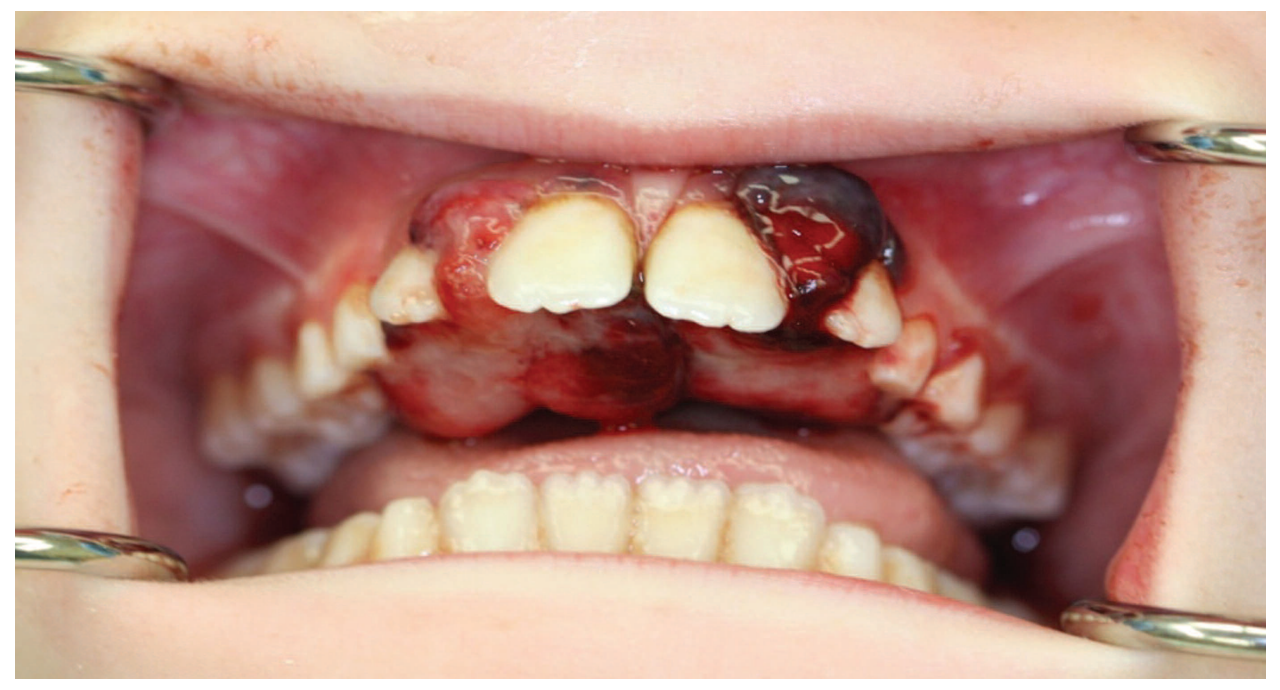

Figure 1. Gingival hypertrophy and friability in our patient with scurvy.

Personal non-commercial use only. The Journal of Rheumatology Copyright @ 2013 . All rights reserved. 


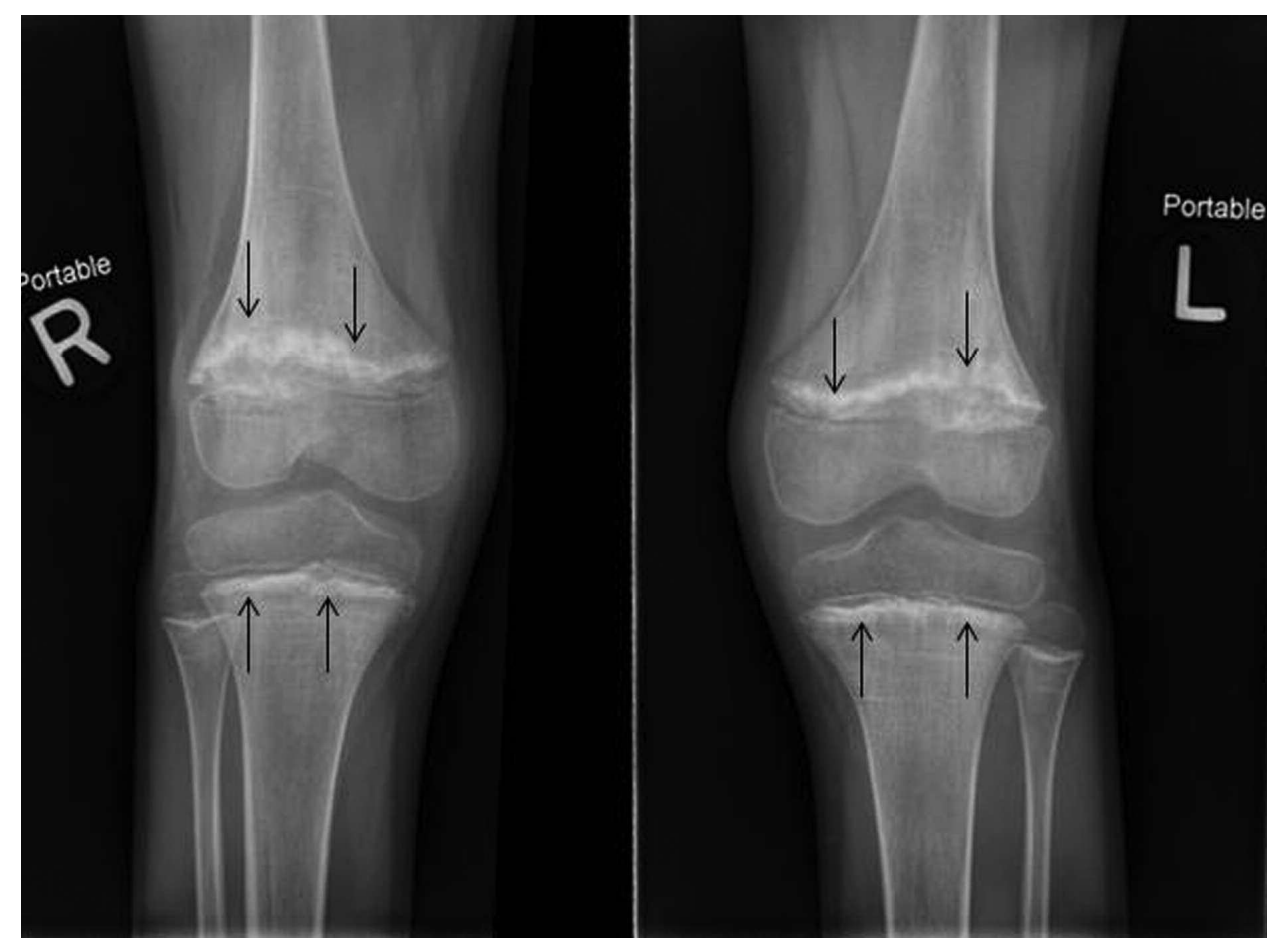

Figure 2. Radiograph of patient's knees showing features of scurvy, including irregularity and lucency at the metaphyses accompanied by regional sclerosis (arrows). Similar but less striking changes are also seen in the proximal tibiae. 